\title{
Fast Charging Electric Vehicle using Fuzzy Logic Controller
}

\author{
G. Madhuri \\ (Assistant Professor) \\ Department of EEE \\ Vignan Institute of Tech \\ \& Science \\ Hyderabad
}

\author{
K. Veena Madhuri \\ (UG Student) \\ Department of EEE \\ Vignan Institute of Tech \\ \& Science \\ Hyderabad
}

\author{
M. Navya \\ (UG Student) \\ Department of EEE \\ Vignan Institute of Tech \\ $\&$ Science \\ Hyderabad
}

\author{
G. Panduranga Reddy \\ (UG Student) \\ Department of EEE \\ Vignan Institute of Tech \\ \& Science \\ Hyderabad
}

\begin{abstract}
The development for the cause of an electric vehicle is air pollution that is being caused by motor vehicles. To reduce the pollution, an electric vehicle is developed but the main problem with an $\mathrm{EV}$ is charging of the vehicle. The vehicle should be charged in an electronic charging station as fast as the motor vehicle is being filled with fuel. In this paper, PID controller, fuzzy logic controller, and a buck-boost controller is present with which the speed of charging an electric vehicle will be increased. The electronic charging station must be able to provide charging of different electric vehicles with different capacities in less duration. This paper provides the information about fast charging of an electric vehicle developed in MATLAB. The optimal performance of the circuit is represented with the help of simulation.
\end{abstract}

\section{Keywords: Electric vehicle EV, Electronic charging station} ECS, Buck-Boost converter, FLC.

\section{INTRODUCTION}

The main reasons for the invention of electric vehicles is the emission of toxic substances into the air by the motor vehicles such as cars, buses, trucks, and so on causing air pollution but the other reason for the development of electric vehicles is that the fossil fuels which are being employed in our daily life will be exhausted not beyond a few years considering the rate of usage. The electric vehicles must be developed in such a way that the vehicle must be charged within a few seconds.

The PID controller used in a fast-charging electric vehicle is always a closed-loop network and receives feedback. This feedback is employed to make adjustments to the deviations in the output. The capacitor bank is used to obstruct the variable DC voltage, the voltage in the transformer is used to step-up or step-down as per the requirements. In the radial distribution system, buffering loads are used, when there are no vehicles in the charging station these loads are utilized to store the electrical energy, the battery is used as a rectifier, and for fast charging purpose the PID controller along with buck-boost converter are used to control the circuit with the FLC.

Buck-boost converter along with the PID controller and FLC is presented as the advanced controlling circuit. The converter is connected to the electric vehicles which are attached to the grid. The FLC can be easily accessible in domestic and industrial based applications. The fuzzy logic can be carried out easily when related with the PID controller and is adaptable to the variations in the system.
In this paper, MATLAB/Simulink is used for the representation of the connections in the network to complete the charging of the electric vehicle quickly.

\section{BUCK-BOOST CONVERTER}

The complete simulation diagram of the EV charging system is advanced in MATLAB/Simulink as presented in Fig. 1. In this figure, the voltage source is modeled as a three phase source and the transformer as a Star-Delta connection. Buck-Boost converter includes the output voltage which may be exceeding or below the input voltage along with is a DC-DC converter. This is even called as a Non Isolating type Converter and Inverting Regulator. Buck-Boost converter may be a sort of switched condition of power supply that mixes the principles of Buck Converter. Therefore the Boost Converter during a single circuit. It gives a regulated DC output voltage where each of two are DC and AC inputs. The input voltage is linked to a device in solid-state. The diode is employed as a second switch.

When the buck converter remains combined with the boost converter, output voltage is usually similar to input, and it can also be below or exceeding than the input. A single inductor can be employed by buck-boost converter which is non-inverting that can be used for both buck and boost inductor mode, employing switches rather than a diode, consistently called a buck-boost converter with four-switch.

There are 2 modes of operation in Buck-Boost converter are: First mode is during the turn on of switch and the turn off of diode, in the second mode switch is off and the diode is on.

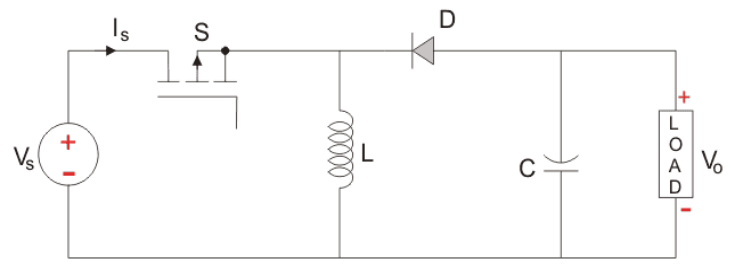

Fig 1: Configuration for buck-boost converter

\section{FUZZY LOGIC CONTROLLER}

Fuzzy logic could be a variety of computer logic that's different from formal logic. The instruction that fuzzy refers to are the things that aren't clear or are uncertain. The real assessment may range in the middle of absolute truth and absolute false as fuzzy logic is utilized for the theory 
of partial truth. In contrast, informal logic, the real assessment of variables may only be the integer values 0 or 1 .

Fuzzy logic could be a way of guessing computers to form decisions more sort of a human would it not uses fuzzy rules and fuzzy sets to model the globe and make decisions about it. Symbolic logic relies on fuzzy sets. Fuzzy sets allow us to pander to the situations that aren't precise. To use symbolic logic in higher cognitive process we want two things fuzzy sets and fuzzy rules.

A fuzzy set could be a collection of related items which belongs thereto set to different degree. Fuzzy rules are justified for asserting pieces of information in "fuzzy logic" as it is the key tool. However, there doesn't exist a novel reasonably fuzzy rules, neither is there just one sort of "fuzzy logic".

The horizontal line in table 1 represents the error and the vertical line represents the change in error. The input that is given to the system in the FLC is the change in between the desired value and the error which is the change in error.

$\begin{array}{clllllll}\varepsilon / \Delta \varepsilon & \text { NB } & \text { NM } & \text { NS } & \text { ZE } & \text { PS } & \text { PM } & \text { PB } \\ \text { NB } & \text { NB } & \text { NB } & \text { NB } & \text { NB } & \text { NM } & \text { NS } & \text { ZE } \\ \text { NM } & \text { NB } & \text { NB } & \text { NM } & \text { NM } & \text { NS } & \text { ZE } & \text { PS } \\ \text { NS } & \text { NB } & \text { NM } & \text { NS } & \text { NS } & \text { ZE } & \text { PS } & \text { PM } \\ \text { ZE } & \text { NB } & \text { NM } & \text { NS } & \text { ZE } & \text { PS } & \text { PM } & \text { PB } \\ \text { PS } & \text { NM } & \text { NS } & \text { ZE } & \text { PS } & \text { PS } & \text { PM } & \text { PB } \\ \text { PM } & \text { NS } & \text { ZE } & \text { PS } & \text { PM } & \text { PM } & \text { PB } & \text { PB } \\ \text { PB } & \text { ZE } & \text { PS } & \text { PM } & \text { PB } & \text { PB } & \text { PB } & \text { PB }\end{array}$

The process of developing the mapping from an accustomed input to an output employing symbolic logic is thought of as fuzzy inference. The FIS is described as a system that employs fuzzy membership functions to form a call.

Fuzzification: FLC rule-based system assess linguistic ifthen rules employing fuzzification inference along with composition procedures. They produce fuzzy results which usually should be converted into crisp output. To move the fuzzy ends up into crisp defuzzification is performed.

Defuzzification: It is the method of converting a fuzzified output into one crisp value with relation to a fuzzy set. The defuzzified value in symbolic logic controller represents the action that should be taken in controlling the method.

So symbolic logic allows computers to mimic human decision-making. Fuzzy sets modern concepts and objectives within the globe. Proficiency is described by fuzzy sets combined using rules and when all of this information is considered into account a call made. These decisions are made using symbolic logic which suggests computing with words.

Table 1: Rules used in fuzzy

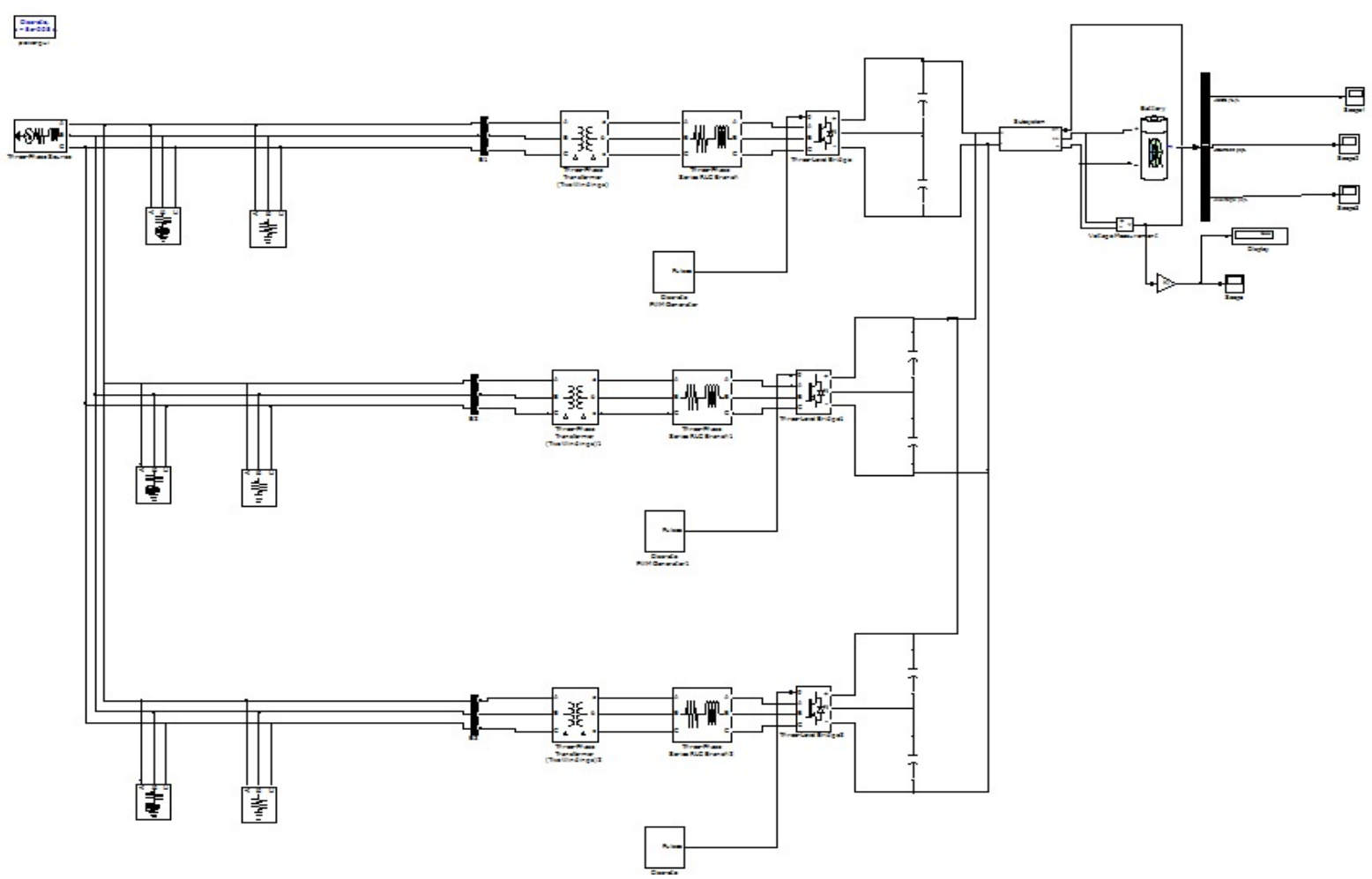

Fig 2: Circuit Design for Fast Charging Electric Vehicle Simulated in MATLAB 


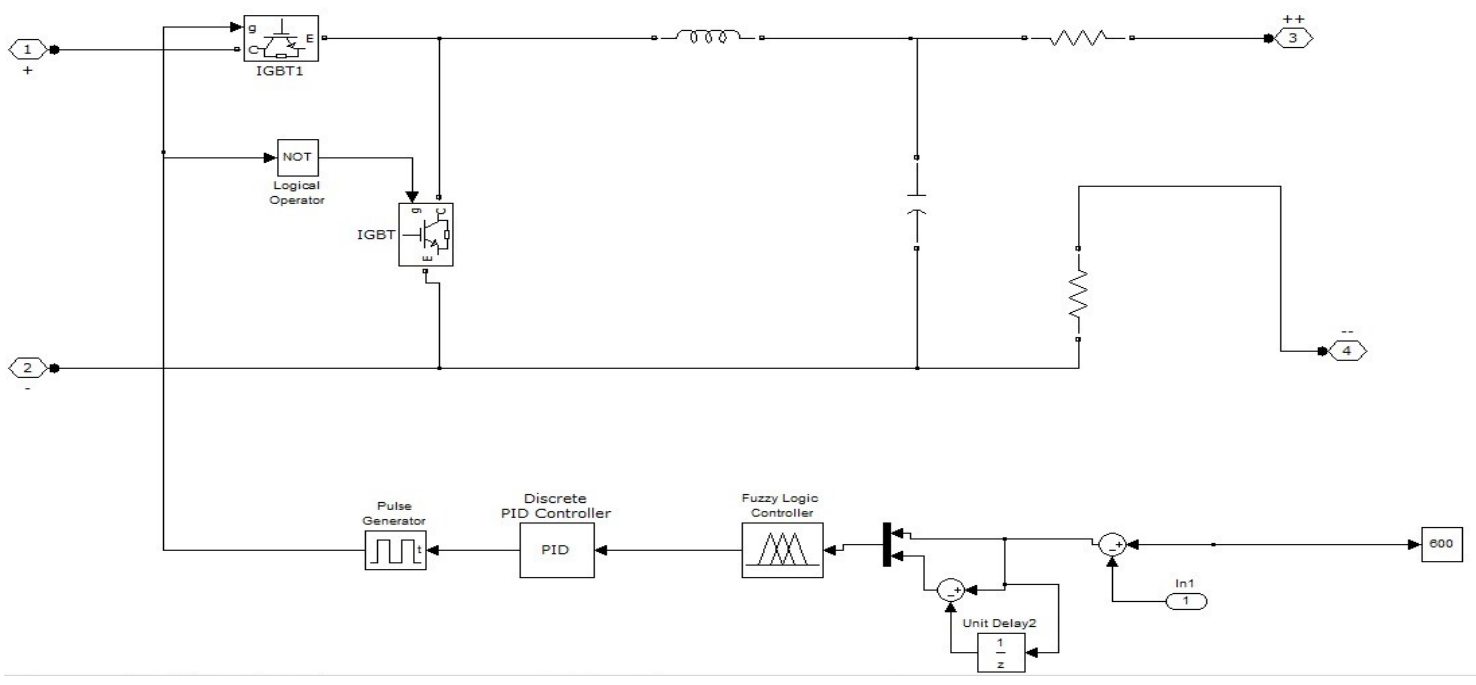

Fig 3: Advanced Control Circuit employing Fuzzy along with PID Controller and Buck-Boost Converter

\section{SIMULATION RESULTS}

When battery charges at constant current, the charging voltage will always be exceeding the open circuit voltage of $324 \mathrm{~V}$ as shown in Fig. 4.

Furthermore, there is a steady rise in battery state of charge (SOC) from $50 \%$ while maintaining a constant DC voltage as shown in Fig 5 and Fig 4.

Fig 6 shows the result for the $120 \mathrm{~A}$ constant current charging for the $12 \mathrm{kWh}$ EV battery. In EV battery, FLC maintains constant current for charging. This result shows the suitability of the FLC for fast DC charging of EV.

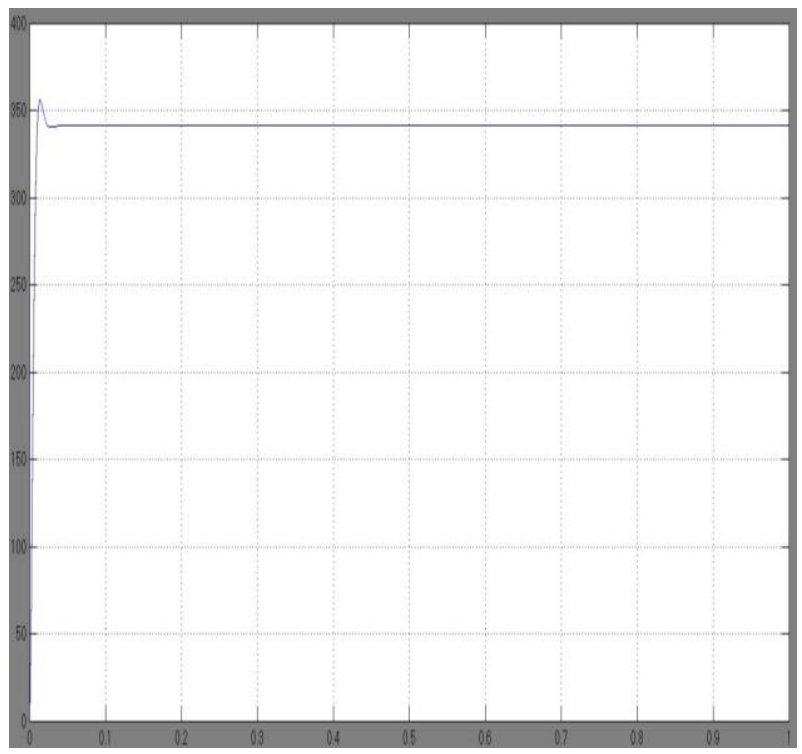

Fig 4: Voltage

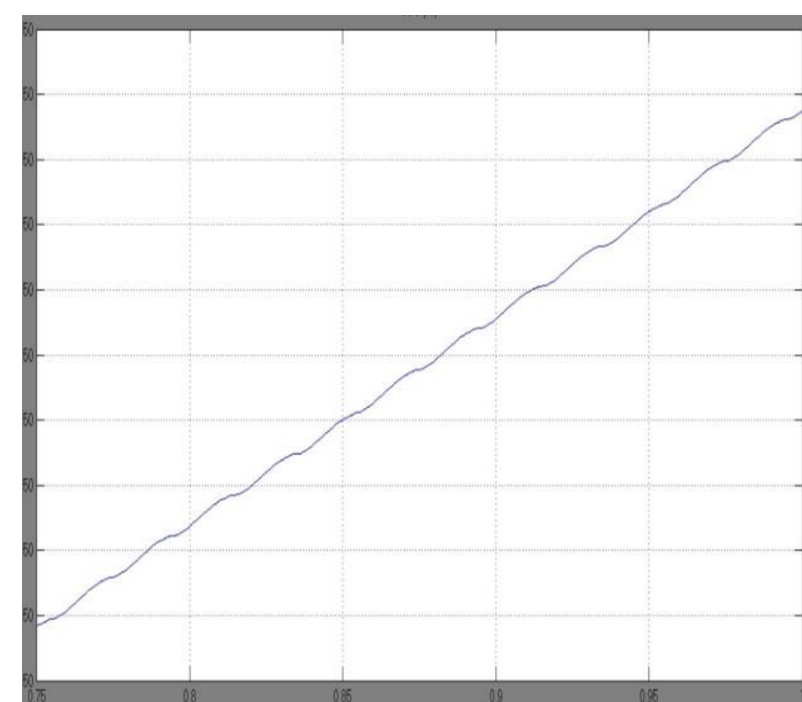

Fig 5: State of Charge

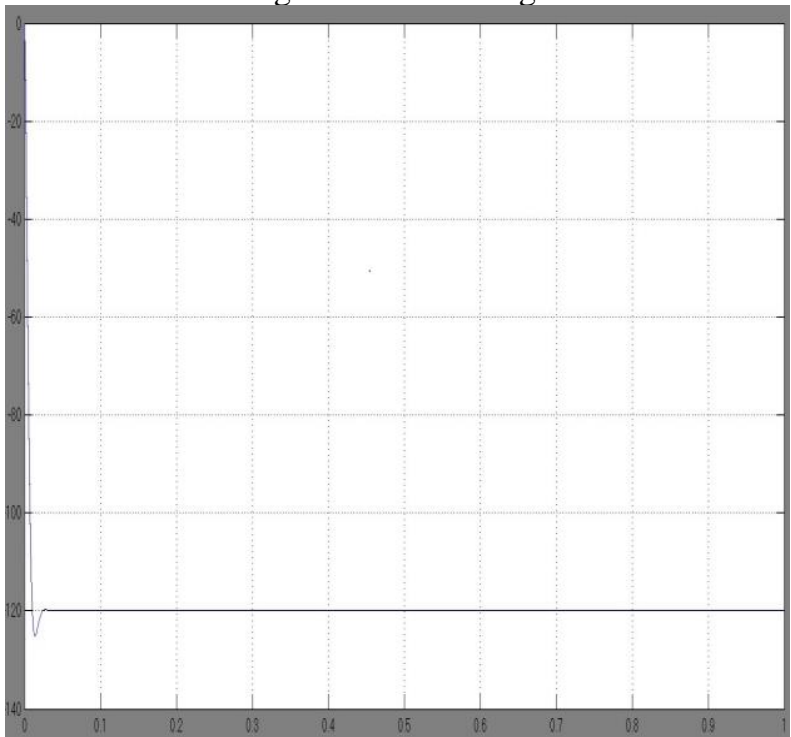

Fig 6: Current 


\section{CONCLUSION}

In view of this paper with the utilisation of fuzzy logic the total model of EV charging system is presented. By using MATLAB, the total simulation design has been advanced. Here it explains about the issues interrelated with fast charging. Slow EV charging time is one of the essential problem with EVs. There will be different electric vehicles with different capacities in an electronic charging station and the customers requires less time for charging the battery. This paper has introduced a system which takes less time (within half a minute) to change the capacity and to charge an electric vehicle. It is also to be known that the manufacturing of EVs and batteries related to EVs would also lead to increase in GDP and will also create new jobs. It is very essential to spread awareness about the EVs. It can be concluded that there will be an immense possibility for EVs in the future.

\section{REFERENCES}

[1] Murat Yilmaz, and Philip T. Krein, "Review of Battery Charger Topologies, Charging Power Levels, and Infrastructure for Plug-In Electric and Hybrid Vehicles," IEEE Trans. Power Electron., vol. 28, no. 5, pp. 2151-2169, May. 2013

[2] Nadia Mei Lin Tan, Takahiro Abe, and Hirofumi Akagi, "Design and Performance of a Bidirectional Isolated DC-DC Converter for a Battery Energy Storage System," IEEE Trans. Power Electron. , vol. 27, no. 3, pp. 1237-1248, Mar. 2012.

[3] Dylan C. Erb, Omer C. Onar and Alireza Khaligh, "Bi-Directional Charging Topologies for Plug-in Hybrid Electric Vehicles," in Proc. IEEE Appl. Power Electron. Conf., Feb. 2010, pp. 20662072.
[4] Kang Miao Tan, Vigna K. Ramachandaramurthy and Jia Ying Yong, "Bidirectional Battery Charger for Electric Vehicle," in Proc. IEEE Innovative Smart Grid Technologies-Aisa, May 2014, pp. 406-411.

[5] Byung-Kwon Lee, Jong-Pil Kim, Sam-Gyun Kim, and Jun-Young Lee, "An Isolated/Bidirectional PWM Resonant Converter for V2G(H) EV On-Board Charger," IEEE Trans. Veh. Technol., vol. 66, no. 9, pp. 7741- 7750, Sept. 2017.

[6] Behnam Koushki, Alireza Safaee, Praveen Jain, Alireza Bakhshai, "Review and Comparison of Bi-Directional AC-DC Converters with V2G Capability for On-Board EV and HEV," in Proc. IEEE Transportation Electrification Conf., June 2014, pp. 1-6.

[7] Serkan Dusmez, and Alireza Khaligh, "Generalized Technique of Compensating Low-Frequency Component of Load Current With a Parallel Bidirectional DC/DC Converter," IEEE Trans. Power Electron., vol. 27, no. 3, pp. 1237-1248, Mar. 2012.

[8] B. Renders, K. De Gusseme, W. R. Ryckaert, K. Stockman, L. Vandevelde, and M. H. J. Bollen, "Distributed generation for mitigating voltage dips in low-voltage distribution grids," IEEE Trans. Power.Del., vol. 23, no. 3, pp. 1581-1588, Jul. 2008.

[9] V. Khadkikar, A. Chandra, A. O. Barry, and T. D. Nguyen, "Application of UPQC to protect a sensitive load on a polluted distribution network," in Proc. Annu. Conf. IEEE Power Eng. Soc. Gen. Meeting, 2006, pp. 867-872.

[10] M. Singh and A. Chandra, "Power maximization and voltage sag/swellride-through capability of PMSG based variable speed wind energy conversion system," in Proc. IEEE 34th Annu. Conf. Indus. Electron.Soc., 2008, pp. 2206-2211.

[11] J. P. Pinto, R. Pregitzer, L. F. C. Monteiro, and J. L. Afonso, "3phase4-wire shunt active power filter with renewable energy interface," presented at the Conf. IEEE Rnewable Energy \& Power Quality, Seville, Spain, 2007.

[12] M. Calais, J. Myrzik, T. Spooner, and V. G. Agelidis, "inverters for single-phase grid connected photovoltaic systems - an overview", in Proc. 33th IEEE Power Electronics Specialists Conf. (PESC'02), Cairns, Australia, June 23-27, 2002. 